\title{
¡¿Es sencillo ser psicoterapeuta?!
}

Is simple to be a psychotherapist?!

Francisco R. Bengoa Ortega ${ }^{a}$, María L. Escamilla Gutiérrez ${ }^{b}$

\begin{abstract}
:
The present essay aims to explain the main problems that psychologists present, in the same way it integrates a different authors' analysis about how to be a good psychologist or psychotherapist.
\end{abstract}

Keywords:

Psychology, psychotherapy, skills.

\section{Resumen:}

El presente ensayo tiene como objetivo explicar los principales problemas que se les presentan a los psicólogos, de igual manera se hace un análisis de diferentes autores acerca de cómo ser un buen psicólogo o psicoterapeuta.

\section{Palabras Clave:}

Psicología, psicoterapeuta, habilidades

\section{Introducción}

¿Qué es un psicoterapeuta? ¿Es lo mismo un psicólogo que un psicoterapeuta? ¿Dar terapia es un don? ¿Se nace o se hace este don? ¿Qué habilidades tiene un psicoterapeuta? En el presente ensayo se cuestiona diferentes miradas desde libros, artículos acerca de la terapia así como las habilidades, actitudes o aptitudes que deben de tener los psicólogos y psicoterapeutas en formación así como los que ya ejercen esta profesión.

\section{Desarrollo}

Chamanes, sacerdotes, brujos, cada uno de ellos desde sus propias posturas y creencias se dedicaron a comprender los malestares del individuo, ya que ellos, no tenían bases científicas, métodos o técnicas para ayudar 0 explicar el comportamiento del ser humano, es así como fueron naciendo los primeros psicólogos y psicoterapeutas con el fin de ayudar, guiar y curar, el malestar del individuo. Pero estos objetivos se fueron interpretando de diferente manera. "La psicoterapia es el único tratamiento que crea la enfermedad que pretende curar"1. En la antigüedad, alguna malformación, retraso mental o en el desarrollo, ante los ojos de la sociedad se veía como algo del mal o del diablo, castigando a esas personas con exilio, encerrándolos o quemándolos. En diferentes momentos de la historia como la edad media, el renacimiento, la edad de la razón y la llustración, hubo personajes como San Agustín Johann Weyer, William Cullen, etc., que estudiaron el comportamiento humano, pero fue hasta Freud en 1909 donde se empezó a catalogar a las personas, al igual que sus propios comportamientos como normales (cuerdos) y anormales (locos). ${ }^{2}$

Con el tiempo se fueron construyendo nuevas perspectivas acerca de las enfermedades, es así como aparece el DSM (Manual diagnóstico y estadístico de las

Autor de Correspondencia, Universidad Autónoma del Estado de Hidalgo, https://orcid.org/0000-0003-0634-5088, Email: fbengoaortega@gmail.com

${ }^{\mathrm{b}}$ Universidad Autónoma del Estado de Hidalgo, Instituto de Ciencia de la Salud, Área Académica de Psicología, https://orcid.org/0000-00026318-4519, Email: maria_escamilla@uaeh.edu.mx 
enfermedades mentales), y sus continuas actualizaciones, llegando a la quinta edición, pasando a tener 66 trastornos, en sus principios, hasta 286 en su cuarta edición, poniendo a la psicoterapia como un mercado importante ${ }^{1}$. Es de esta manera como la imagen de un psicólogo, psicoterapeuta o la de un psiquiatra se ha malinterpretado llevando a estas profesiones a una desvaloración, a nivel profesional, social o de manera económica.

En un principio un estudiante de psicología entra a esta carrera para "ayudar a la gente" o "dar consejos". Conforme van pasando los semestres estas ideas van cambiando así como el panorama de la psicología va creciendo, con el autoconocimiento personal y profesional. Algunos libros recomendados por maestros ayudan al alumno a percibir el mundo y la profesión de manera diferente.

En la actualidad existe una gran literatura dirigida a estudiantes de psicología así como de psicoterapia, el don de la terapia de Irvin D. Yalom ${ }^{3}$ es uno de ellos, en el cual se pueden leer varias ideas, consejos, sugerencias que pueden servir a todo profesional, Irvin hace reflexionar al lector sobre las cualidades que debe de tener un psicólogo... no es lo mismo "oír" que "escuchar" al igual que "entender" y "comprender", verbos que el psicólogo debe de tener bien definidos para ejercer su profesión, cualidades como son: la creatividad en cada paciente, saber hacer preguntas con las cuales se pueda mover al paciente, quedarse callado en tiempos necesarios aunque no se sepa que decir, la empatía, trabajar con el aquí y el ahora, hacer notas en el momento adecuado, hablar sobre los tabúes entre otras más, se describen en el don de la terapia. El ser humano está en constante aprendizaje, independientemente de ser un profesional 0 un estudiante, es necesario mirarse y escucharse a uno mismo. Irvin muestra en su libro la auténtica relación entre el terapeuta y el paciente, además que se puede aprender de una sesión de terapia ya que el paciente puede enseñar al terapeuta puntos ciegos de los cuales el profesional no se había dado cuenta, es decir, el autor da a entender con palabras simples que lo que cura no es la técnica psicoanalítica o cognitivo-conductual, sino la simple relación, la confianza que se brinda en la dinámica de Terapeuta-Paciente o viceversa.

Se han creado manuales en los cuales se recoge y documenta diferentes modelos como el de Ellis, Beck, Nezu, Wessler, Young ${ }^{4,5}$, con el fin de mostrarle al lector la gran variedad de terapias que existen en el mundo y así pueda elegir el modelo que más le atraiga; de igual manera se describen la primera, segunda y tercera generación por las que ha pasado el modelo cognitivo-conductual, para tener una base sólida en la actualidad, también se mencionan diferentes técnicas que se han comprobado empíricamente en diferentes poblaciones y psicopatologías y que han tenido fructuosos resultados; así como la estructura de la entrevista conductual, la asignación de tareas para posteriores sesiones y distintas habilidades que debe de tener un psicoterapeuta. Hoy en día se necesitan psicólogos y psicólogas que tengan fundamentos teóricos y de practica que estén basados en la evidencia empírica y de los cuales han sido sometidos a prueba científica con buenos resultados, con el fin de brindar mejores resultados en sus intervenciones. ${ }^{6}$

El terapeuta siempre va a buscar crear una relación, la cual puede existir de diferentes formas con diferentes maneras de reflexionar en cada una de ellas: ${ }^{7}$

1. Relación terapeuta-paciente: Socialmente al terapeuta se le ha dado el poder de brindar la ayuda al otro, a comprender, entender, curar al individuo con algún malestar emocional, físico o social.

2. Relación e identidad cultural: En palabras de la autora es "ponerse en la perspectiva de comprender al otro, implica, para el terapeuta, reconocer la otra cara del conocimiento", es decir, entrar en la subjetividad de cada cultura, ya que en el consultorio pueden llegar individuos de otros países que necesitan ser comprendidos, aceptados y no juzgados.

3. Relación terapéutica y la educación: Se ve al profesional como alguien experto en conocimientos de su carrera. Con el paso del tiempo los pacientes han identificado sus propios síntomas y autodiagnosticándose, es por ello que la relación con la propia educación del psicólogo es importante para ser más objetivos, certeros, eficaces y eficientes en una sesión de terapia.

4. Relación terapéutica y el uso de la tecnología: Así como el terapeuta está en constante actualización de conocimientos, el uso de las tecnologías puede aportar nuevas ideas y alternativas de solución a un problema, sin embargo, también puede ser contraproducente para la relación con el otro, pues se ha llegado a pensar que ya no existe una interacción entre personas, sino entre pantallas.

Como se puede apreciar, se está en constante comunicación o relación, no solo con las personas, sino con diferentes profesiones, cultura, medios de comunicación etc., es por ello que es indispensable el saber cómo relacionarse con el medio que nos rodea y más para un psicólogo. El mundo está en constante metamorfosis en la cual, las relaciones han ido cambiando, creando nuevas formas de comunicar, causando nuevos problemas. Parte de las tareas de un psicólogo o psicoterapeuta es enriquecer el conocimiento científico, para crear nuevas teorías que devengan en nuevas formas de intervenir y ayudar a los otros. 


\section{Conclusiones}

La psicología es una de las profesiones más complicadas y versátiles que existen, pues entender a cada ser humano en las diferentes etapas de su vida en contextos o culturas diversas, es un trabajo que no se encuentra en internet o en los mismos libros de psicología o teorías de la personalidad. El ser o no ser un buen psicólogo no está definido por el conocimiento, los libros de psicoanálisis o manuales cognitivos-conductuales que se lean; habrá características, cualidades, actitudes que se deben desarrollar, para ser un buen psicólogo. Tal vez haya personas que tengan el don de dar terapia o no lo tengan... En esta profesión es necesario estar en constante aprendizaje, esforzase cada día, con el fin de ser mejor psicólogo, con o sin título y más que nada, ser mejor persona, ya sea yendo a terapia, leyendo, asistiendo a cursos o diplomados, eligiendo una maestría, haciendo trabajo de investigación la cual aporte a la psicología nuevo conocimiento como es la creación de nuevas intervenciones de psicoterapéutica, todo esto para brindar un buen apoyo psicológico a las personas que lo requieran.

En conclusión: ¡no es sencillo ser psicólogo o psicoterapeuta!

\section{Referencias}

[1] Campagne DM. El terapeuta no nace, se hace. Rev Asoc Esp Neuropsiq. 2013; 34: 75-95.

[2] Sarason IG y Sarason BR. Psicopatología: Psicología anormal: el problema de la conducta inadaptada. Unadecima ed. México: Pearson; 2006.

[3]Yalom ID. El don de la terapia. 2da ed. España: Emecé; 2003.

[4] Caro I. Manual teórico-práctico de psicoterapia cognitivas. 2da ed. España: Desclée; 2009.

[5] Ruíz MA, Díaz MI, Villalobos A, editores. Manual de técnicas de intervención cognitivo conductuales. 1era ed. España: Desclée; 2012.

[6] Ybarra JL, Orozco, LA, Valencia A, editores. Intervenciones con apoyo empírico: herramienta fundamental para el psicólogo clínico y de la salud. 1era ed. México: Manual moderno; 2015.

[7] Ospina DE. La relación terapéutica-paciente en el mundo contemporáneo. Invest Edu enferm. 2008; 26: 116-122. 